\title{
Discussion on Implementation and Supervision of Safety Production Responsibility of Construction Engineering Enterprises
}

Yan Zhao

Qingdao Chengyang Construction Engineering Service Center, Qingdao 266109, Shandong Province, China

\begin{abstract}
In order to improve the safety production management ability of construction enterprises in an all-round way and implement the main responsibility of enterprise safety production, the government supervision department should play its own important role, adhere to the implementation of system requirements and supervision work principles according to the safety production responsibility, carry out overall planning and reasonable deployment for the safety production problems of construction engineering enterprises in many aspects. Through the continuous standardization of construction enterprise safety production work behavior, to curb the occurrence of all kinds of safety production accidents. This paper mainly stands in the perspective of the supervision department, studies and analyzes the implementation of safety production responsibility and supervision measures of construction engineering enterprises, for reference only. Key word: Architectural engineering; Enterprise safety production; Responsibility implementation; Supervise
\end{abstract}

Publication date: July, 2020

Publication online: 31 July, 2020

*Corresponding author: Yan Zhao,ma1392020@163. com

\section{Introduction}

Safety production is always the key practice of construction engineering enterprises. It is required that all construction enterprises should be brave enough to take on their own work responsibilities, and carry out accurate optimization and reasonable implementation of on-site construction content and management content in strict accordance with the requirements of safety production responsibility system of construction engineering enterprises. However, combined with the current situation, because some construction enterprises are not qualified and have weak awareness of safety production concept, accidents often occur during the construction period due to the interference of uncertain factors. At present, in order to further strengthen the standardization of safety production of construction enterprises, the relevant regulatory departments of the government should shoulder their own functions and responsibilities. Based on the local actual situation, the government should reasonably implement the work plan for the main responsibility of construction enterprises in safety production, so as to ensure that the production behaviors of construction enterprises can be standardized in the process of strong supervision, and promote the construction industry in China Benign development.

\section{Implementation principle and requirement analysis of safety production subject responsibility of construction engineering enterprises}

\subsection{Production and operation according to law}

Construction enterprises must establish a good concept of the rule of law, always adhere to the bottom line of law, and realize production and operation according to law. In other words, construction enterprises must meet the national laws and regulations standards or industry standards in production and operation activities. Among them, the safety production conditions should be reasonably implemented in accordance with national 
laws and regulations standards or industry standards. If the construction safety production license must be obtained, the corresponding production activities can be carried out. During production and operation, it is forbidden to command or operate in violation of regulations. At the same time, illegal subcontracting and arbitrary reconstruction and expansion are strictly prohibited.

\subsection{Safety responsibility in place}

Construction enterprises should be based on the requirements of engineering safety construction, improve, and optimize the safety production management organization. And always in accordance with the requirements of post safety production responsibility system, fully implement the content of post responsibility system. On this basis, the scientific and reasonable safety responsibility assessment standard and the content of reward and punishment system are formulated. It is better to achieve the goal of double responsibility in safety production under the management of leaders. In addition, we should deepen and strengthen safety management. The site management can be carried out by the construction personnel on a regular basis. Once the hidden danger is found, it must be handled in time to ensure the safety of production and operation.

\subsection{Safety input in place}

Construction enterprises should set up professional accounts according to the requirements of laws and regulations, and implement special funds for special purposes. Only when the safety investment is put into place, can it provide a good guarantee for the smooth development of safety training and education as well as the assessment and reward of safety production responsibility system. At the same time, after the safety investment is in place, the construction enterprise should purchase the corresponding labor protection articles for all employees. According to the requirements of relevant laws and regulations, purchase insurance for personnel engaged in hazardous work, such as accidental injury insurance, and earnestly implement and implement the safety production responsibility of construction enterprises ${ }^{[1-2]}$.

\subsection{Safety training in place}

Construction enterprises should carry out regular safety production training and education for site participants in accordance with national laws and regulations. Based on the construction requirements and risk management principles of construction engineering, the overall planning and reasonable deployment of safety production training and education content can be carried out from many aspects. At the same time, it is required that the technical responsible personnel and the main responsible personnel must hold the post certificate. In addition, the relevant personnel engaged in special construction operations should be handed over to the construction administrative department for training and management. For example, professional safety knowledge and skills training can be carried out to deepen the safety construction concept awareness of relevant operators.

\subsection{Safety management in place}

Construction enterprises should strictly implement and implement the management content of safety production system. It is better to start from the field management, and carry out preventive treatment for the potential safety problems existing in the construction site. At the same time, fully implement and implement various safety inspection systems to ensure the smooth realization of the construction safety production standardization construction goal. And on this basis, actively promote and apply the new technology and new process content to ensure that the safety level of construction enterprises can be improved in an all-round way ${ }^{[3]}$.

\subsection{Emergency rescue in place}

In addition to implementing the above safety production responsibility, construction enterprises also need to make overall planning and reasonable deployment for emergency rescue work. It is suggested that construction enterprises should strengthen the level of emergency management. According to the business scope of the enterprise and possible risk accidents, the corresponding emergency plan shall be formulated. And on this basis, according to the construction situation of the construction site, strengthen the special emergency drill to ensure that everyone has a strong sense of safety prevention.

\section{Research on the supervision measures for the implementation of safety production responsibility of construction engineering enterprises}

In order to ensure that the safety production responsibility of construction engineering enterprises can be fully implemented, the government supervision departments should shoulder their own work responsibilities, adhere 
to the principle of "one must five in place", and urge the effective implementation of safety production responsibilities of construction engineering enterprises. The following is a summary and summary of supervision measures for the implementation of safety production responsibility of construction engineering enterprises based on relevant experience for reference.

\subsection{Comprehensively strengthen publicity and guidance to create a good public opinion atmosphere}

The government supervision department should take various forms to comprehensively strengthen the propaganda and guidance, so that each construction enterprise can make clear the significance and main requirements of the main responsibility of safety production. At the same time, the government regulatory departments should pay attention to the typical, promote the advanced, and focus on the warning and deterrent function and role. Among them, for the enterprises that do not carry out work according to the requirements or the implementation efficiency of the main responsibility of safety production is not high, the government regulatory authorities should put them into the key supervision areas, and strictly investigate and deal with them. In addition, for the construction enterprises with serious illegal and dishonest behaviors, the government regulatory department should incorporate it into the market integrity assessment system. And on this basis, timely feedback on the implementation of its special action is carried out, in order to create a good public opinion atmosphere and further standardize the safety production behavior of construction enterprises ${ }^{[4]}$.

\subsection{Pay close attention to implementation and strengthen supervision and law enforcement}

Government supervision departments should always adhere to the unified leadership of the government, cooperate with relevant departments to realize the process of joint action. Among them, special actions can be taken to carry out various work for the implementation of the main responsibility of safety production in construction enterprises. For example, the participating departments can hold relevant meetings on a regular basis to provide guidance on the progress of the activities and existing problems. It should be noted that the government regulatory departments should strictly crack down on illegal production and operation in accordance with the principle of strict implementation, to standardize the development order of the construction market. In addition, the regulatory authorities should strengthen the supervision and law enforcement, adhere to the principle of focusing on driving the general, so as to further promote the benign development of China's construction industry production behavior.

\subsection{Improve the long-term mechanism to prevent production safety accidents}

The government supervision department should carry out overall planning and reasonable deployment for the implementation of the main responsibility of safety production of construction enterprises on a regular basis. For example, it can realize the integrated development of relevant activities and major work such as safety production inspection and special rectification. And according to the actual situation, we should improve the long-term mechanism, standardize the behavior of the main body of production, and consciously implement the main responsibility. Among them, we must attach great importance to the safety management problems involved in the construction site construction. It is better to strengthen the supervision on the production behavior of construction enterprises, make them deeply aware of the importance of their own work, and try to prevent production safety accidents from many aspects.

\section{Conclusion}

In a word, the government supervision department should strengthen the supervision of construction enterprises. Focus on the work of safety production publicity and the main responsibility of enterprises to carry out a clear grasp and analysis. By constantly promoting the implementation of corporate responsibility, the goal of government supervision can be achieved smoothly. During this period, the relevant personnel engaged in the supervision of construction engineering safety production should be deeply aware of the importance of their own work, and strictly in accordance with the work standards and relevant principles, the daily supervision work content should be planned and reasonably implemented. In addition, the relevant personnel should clearly grasp the specific causes of previous construction production safety accidents, find out the causes in time, and put forward targeted preventive measures, so as to curb the production safety accidents.

\section{Reference:}

[1] Cao J. Quantitative research on safety responsibility performance of construction enterprises [D]. China University of 
Geosciences (Beijing), 2018

[2] Wang CR. Research on government supervision of construction safety based on game theory [D]. Chongqing University, 2012.

[3] Huang J. Analysis of the current situation of construction safety in China and Discussion on countermeasures[J]. Anhui architecture, 2014, 21(4): 237-238.

[4] He HT. Current situation and treatment analysis of construction safety production [J].Jiangxi building materials, 2016(1): 289. 